\title{
Efficacy of Sanitizers on Three Types of Tropical Fruits Having Different Skin Characteristics
}

\begin{abstract}
Keywords: Sanitizers; Minimal processing; Fruit-surfaces; E. coli; S. aureus; Biofilms

Abstract

The efficacy of removal of known concentrations of $E$. coli and Staphylococcus aureus from the fruit surfaces by differen concentrations of Chlorine Dioxide, Hypochlorite, Hydrogen Peroxide, water and heat treatments were studied on three tropical fruits, sta fruit, guava and pineapple. It was found that S. aureus was more difficult to remove than E.coli from the surface of guava than from star fruit but pineapple skin offered the highest resistance. This may be due to the firmer attachment of S. aureus to fruit surfaces than E. coli, due to their ability to form biofilms. Star fruit's smooth, waxy cuticle, possibly discourage bacteria from adhering to its surface compared to guava. Most of the same treatments were only able to reduce the bacteria cells by $<1$ log CFU in the case of pineapple. The rough pineapple skin would probably encourage firm attachment of bacterial cells and also shield them from sanitizing agents.
\end{abstract}

\section{Introduction}

The growth of value added fresh fruit and vegetable produce supermarket sales in the US has increased by as much as 10.9 and $18 \%$ over the period from 2006 to 2011 [1]. According to a recent survey done by the University of California Davis reported in the January issue of Fresh Cut Magazine, the projected annual sales of fresh cut in the US was $\$ 11$ billion [2]. With this phenomenal growth of the minimal processing industry comes the safety-issues of these products.

Fresh-cut produce, by definition, has been injured through peeling, cutting, slicing, or shredding. These operations can transfer pathogenic microorganisms, if present, from the surfaces of the intact fruit or vegetable to the internal tissues because injured cells released cell fluids thus providing a nourishing environment for microbial growth.

Outbreaks of human infections associated with the consumption of raw fruits, vegetables, and unpasteurized fruit juices have increased in recent years. There have been documented associations of shigellosis with lettuce, scallions, and parsley; cholera with strawberries; parasitic diseases with raspberries, basil, and apple cider; hepatitis A virus with lettuce, raspberries, and frozen strawberries; and Norwalk/Norwalklike virus with melon, salad, and celery [3]. Among the greatest concerns with human pathogens on fresh fruit and vegetables are the enteric pathogens (e.g., E. coli O157:H7 and Salmonella) that have the potential for growth prior to consumption or have a low infectious dose $[4,5]$.

Several reasons for the increase in produce-related human infections have been proposed. These include changes in dietary habits, including a higher per capita consumption of fresh or minimally processed fruits and vegetables, and the increased use of salad bars and meals eaten outside the home and food reformulation

\section{Journal of Food Processing \& Beverages}

Kiang Kin $\operatorname{Har}^{1}$ and Conrad O. Perera ${ }^{1 *}$

Department of Chemistry, FST Programme, National University of Singapore, Singapore 117543

\section{Address for Correspondence}

Conrad O. Perera, School of Chemical Sciences, The University of Auckland, Private Bag 92019, Auckland 1142, New Zealand, Tel: (+649)9233156; Fax: (+649)-3737422; E-mail: conradperera@Gmail.com

Submission: 17 July 2013

Accepted: 05 August 2013

Published: 12 August 2013

for improved health [6,7]. In a recent review article, Skovgaard [8] discussed the effect of sublethal stresses on bacteria and how exposure to one stress factor can confer resistance to other stresses, causing a series of contagious resistances. The implication of this in modern approaches of food preservation, such as minimally processed foods, is considerable.

There are a variety of methods used to reduce populations of microorganisms on whole or fresh-cut fruits and vegetables. They include chemical sanitizer and heat treatments. Efficacy of the sanitizers used to reduce microbial populations is usually dependent upon the type of treatment, type and physiology of the target microorganisms, characteristics of produce surfaces (cracks, crevices, texture and hydrophobic tendency), exposure time and concentration of sanitizer, $\mathrm{pH}$, and temperature [9].

Numerous studies have been conducted to evaluate the efficacy and effectiveness of sanitizing treatment on different produce [10-13]. However, most of the studies were conducted on temperate fruits.

Therefore the aim of this experiment was to study the efficacy of removal of microorganisms especially E.coli (ATCC 25922) and S. aureus (ATCC 25923) from the surface of three tropical fruits, namely, guava, star fruit and pineapple by different sanitizer and heat treatments.

\section{Materials and Methods}

Guava (Psidium guajava), dwarf variety of pineapple (Ananas) and star fruits (Averrhoa carambola) were purchased from a local fresh market a day before the experiment. The fruits were stored refrigerated at $5^{\circ} \mathrm{C}$ and placed at room temperature $\left(22^{\circ} \mathrm{C}\right)$ for about 3 hours before use. Mature fruits were chosen with minimum lesions on their surfaces.

Sanitizer solutions of bleach, equivalent to $200 \mathrm{ppm}$ Chlorine, $5 \%$ $\mathrm{H}_{2} \mathrm{O}_{2}$ solutions, $10 \mathrm{ppm}$ Aqua-Plus 5 (Chlorine Dioxide, Bio-Cide International Inc., Oklahoma, USA) and a heat treatment of $80^{\circ} \mathrm{C}$ for $60 \mathrm{sec}$ (but for pineapple, a heat treatment of $80^{\circ} \mathrm{C}$ for $2 \mathrm{~min}$ ) were used for surface decontamination of the fruits. The microorganisms used in this study, Staphylococcus aureus (S. aureus ATCC 25923) and Escherichia coli ATCC25922 were obtained from the Department of Microbiology, National University of Singapore. They were maintained at $4^{\circ} \mathrm{C}$ in tryptic soy agar. 


\section{Procedure for Inoculation}

The colonies of each microorganism maintained on tryptic soy agar were transferred to $10 \mathrm{~mL}$ of tryptic soy broth and incubated at $35^{\circ} \mathrm{C}$ for $24 \mathrm{hr}$. The bacterial populations were enumerated by Absorbance of the respective bacterial suspensions at a wavelength of $590 \mathrm{~nm}$. The final concentration of each bacterial inoculum was approximately $10^{8} \mathrm{CFU} / \mathrm{mL}$.

The surfaces of Guava, star fruit and pineapple were treated with ethanol, washed in sterile water and dried in a sterile laminar flow cabinet. The sterilized and dried fruit surfaces were inoculated with a total of $100 \mu \mathrm{L}$ of the respective bacterial suspensions applied in about10-20 spots on the surface to facilitate quick drying. The fruits were then left in the laminar flow cabinet for the inocula to dry.

\section{Procedure for Fruit Treatment}

The inoculated fruits were subjected to different sanitizer treatments as follows. For the first treatment, the fruits were individually immersed in $1000 \mathrm{ml}$ of $200 \mathrm{ppm}$ chlorine solution for $5 \mathrm{~min}$. The second treatment involved dipping each fruits in 1000 $\mathrm{ml}$ of $5 \%$ hydrogen peroxide for $5 \mathrm{~min}$. The third treatment solution contained $10 \mathrm{ppm}$ of Aqua plus 5 (Chlorine dioxide) and the fruits were respectively dipped in it for $5 \mathrm{~min}$. The fourth treatment was a heat treatment whereby respective fruits were subjected to $80^{\circ} \mathrm{C}$ steam for $2 \mathrm{~min}$ (for pineapples) and 60 seconds (for guavas and starfruits) and the fifth was dipping in sterile deionized water for $5 \mathrm{~min}$. After treatments, each fruit was rinsed with $1000 \mathrm{ml}$ of sterile deionized water thrice to remove residual chemicals. Inoculated fruits that were not subjected to any sanitizer treatment were rinsed with $1000 \mathrm{ml}$ sterile deionized water and were used as control samples.

The fruits subjected to treatments as above were placed in sterile Zip-Loc bags and 50mL (for guava and star fruit) and $100 \mathrm{~mL}$ (for pineapple) of sterile $0.85 \%$ saline solutions were added. The bag and contents were thoroughly shaken for 10 minutes and the resulting saline solutions were appropriately diluted, and E. coli and S. aureus were enumerated by plating on MacConky and Baird Parker agar respectively. Control samples were carried out in exactly the same way without the bacterial inoculations. To obtain baseline data (fruits received no treatments), fruits were individually placed in a Ziploc bag and $50 \mathrm{ml}$ (for starfruits, guavas) or $100 \mathrm{ml}$ (for pineapples) of $0.85 \%$ sterile saline water was added to the fruit in the bag, and thoroughly shaken for 10 minutes. The resulting saline solutions were appropriately diluted and analyzed for E. coli and S. aureus.

\section{Statistical Analysis}

Data from independent replicate trials were pooled and the mean and standard deviations were determined using Microsoft Excel 98 for each of the analysis. Significant difference between different results were determined by $\mathrm{t}$-test and ANOVA at $\mathrm{p}=0.05$.

\section{Results}

E. coli (ATCC 25955), S. aureus (ATCC 25955) recovered from untreated inoculated fruits are shown in Tables 1 and 2 . The effect of various sanitization treatments on E-coli and S. aureus inoculated onto fruits are shown in Figures 1-3).

\section{Discussion}

Complete recovery of inoculated bacteria from surfaces of fruits was not observed (Tables 1 and 2). The decrease in population of bacteria on the fruit after inoculating and drying might be due to limitation of nutrients for the bacteria, drying of inoculum, or competitive microbes [14]. Beuchat et al. [15] found that E. coli O157:H7 was adversely affected by drying process, with population decreasing from 6.88 to $3.85 \log \mathrm{CFU} /$ fruit within 2 hour at $22^{\circ} \mathrm{C}$.

This observation was unexpected. According to Archer and Crossley [16], S. aureus is noted to be one of the most resistant non-spore-forming human pathogens and can survive for extended periods in a dry state. It is also stated that $S$. aureus is much more tolerant to drying than $E$. coli. Such discrepancy from the test results may be due to competition between $S$. aureus and E. coli as both bacteria were inoculated onto the same fruit.

Moreover, it is also possible that $S$. aureus was more firmly attached to the surface of fruits than E. coli, thus it was difficult to recover them. In a study conducted by Rossoni and Gaylarde [17] with the use of epifluorescence microscopy, they were able to observe that $S$. aureus were more adhesive than E. coli to the surface of stainless steel due to the formation of biofilms.

\section{Star Fruit and Guava}

Generally the effectiveness of various treatments on E. coli and S. aureus on the surface of star fruits and guavas was similar. The only notable difference was that reductions of these bacteria on star fruits were generally higher than guavas. The differences in the level of reduction of bacteria in star fruit and guava by the sanitizer treatment may be due to the morphology of the fruits. Star fruits have a relatively smooth and waxy cuticle that can possibly discourage bacteria from adhering to its surface $[18,19]$. Thus loose bacterial cells are easily removed from star fruit resulting in higher population reductions than in guava. Guava, unlike star fruit, has a rough surface with many small pores. Inoculated bacterial cells may attach to these sites and becomes less accessible to sanitizer solutions. As a result, the bacterial population reduction for most treatments in guavas would be smaller as noted in the Figures 1 and 2.

Solution of $5 \%$ hydrogen peroxide was the most effective treatment in reducing E. coli from the surface of star fruit and guava. Water alone reduced E. coli population from star fruit and guava by 2.57 and $1.18 \log$ CFU. Whereas, 5\% hydrogen peroxide significantly improved the reduction of bacteria by 4.02 and $2.09 \log$ CFU for the respective fruits.

Table 1: E. coli (ATCC 25922) Recovered from fruit surfaces after inoculation.

\begin{tabular}{|c|c|c|c|}
\hline \multirow{2}{*}{ Inoculum } & \multicolumn{3}{|c|}{ Populations (Log CFU/fruit) } \\
\hline & Star fruit & Guava & Pineapple \\
\hline Population Recovered & 7.80 & 7.92 & 7.79 \\
\hline Log reduction & 7.03 & 6.91 & 5.56 \\
\hline
\end{tabular}

Table 2: S. aureus (ATCC 25923) Recovered from fruit surfaces after inoculation.

\begin{tabular}{|c|c|c|c|}
\hline \multirow{2}{*}{} & \multicolumn{3}{|c|}{ Populations (Log CFU/fruit) } \\
\hline Inoculum & Star fruit & Guava & Pineapple \\
\hline Population Recovered & 7.72 & 7.99 & 7.71 \\
\hline Log reduction & 6.16 & 6.14 & 5.23 \\
\hline
\end{tabular}


The effectiveness of hydrogen peroxide was demonstrated by various people. Park and Beuchat [20] observed that $1 \%$ hydrogen peroxide was able to reduce E. coli $\mathrm{O} 157: \mathrm{H} 7$ on cantaloupes by 2.3 $\log \mathrm{CFU}$, compared to water rinse of inoculated fruit. Yu et al. [21] found that $3 \%$ hydrogen peroxide was able to reduce inoculated $E$. coli $\mathrm{O} 157: \mathrm{H} 7$ by $2.2 \mathrm{log} \mathrm{CFU}$ on strawberry, whereas water alone was only able to reduce the population by $0.8 \log$ CFU. Sensitivity of $E$. coli to hydrogen peroxide as opposed to other chemicals may be due to the lack of glutathione peroxidase in E. coli, which cannot use glutathione for enzymatic catabolism of hydrogen peroxide [22]. Thus from Figures 1 and 2, it appears that 5\% hydrogen peroxide exhibited a much larger kill against $E$. coli than $S$. aureus.

Effect of chlorine on E. coli has been widely studied and was found to be ineffective against this species of microorganism. Sapers et al., [12] demonstrated that dipping inoculated apples in $200 \mathrm{ppm}$ chlorine solution for $1 \mathrm{~min}$ was not effective in reducing E. coli; only $0.5 \log$ CFU/g reduction was achieved. Likewise, Beuchat [23] found that $200 \mathrm{ppm}$ chlorine was no more effective at removing $E$. coli O157:H7 than treatment with deionized water. These findings were similar to what was observed in the present study. For guava, 200 ppm chlorine did not significantly reduced $E$. coli populations as compared to water. However, reduction of $E$. coli with $200 \mathrm{ppm}$ chlorine on star fruit was significantly higher compared to that using water alone. Water was able to reduce the population by $2.57 \log \mathrm{CFU}$, while 200 ppm chlorine reduced the population by $3.45 \log$ CFU.

Aqua plus 5 is a chlorine dioxide based sanitizer. From Figures 1 and 2, it was observed that dipping star fruits and guavas in $10 \mathrm{ppm}$ of Aqua plus 5 solution, for 1 minute was comparable to that of water in reducing E. coli population. There was no significant difference between these two treatments. The relatively ineffectiveness of chlorine dioxide solution on E. coli was also noted by Pao and Davis [13]. In their study they found that immersion of oranges in $100 \mathrm{ppm}$ chlorine dioxide solution for as long as 8 min could only produce a 3-log reduction of E. coli compared to about 2-log reductions when immersed in water alone.

Pao and Davis [13] were able to demonstrate that hot-water immersion was able to reduce inoculated E. coli from oranges effectively. A 5-log reduction was achieved by immersing inoculated fruit in hot water at either $80^{\circ} \mathrm{C}$ for $2 \mathrm{~min}$ or $70^{\circ} \mathrm{C}$ for $4 \mathrm{~min}$. Water

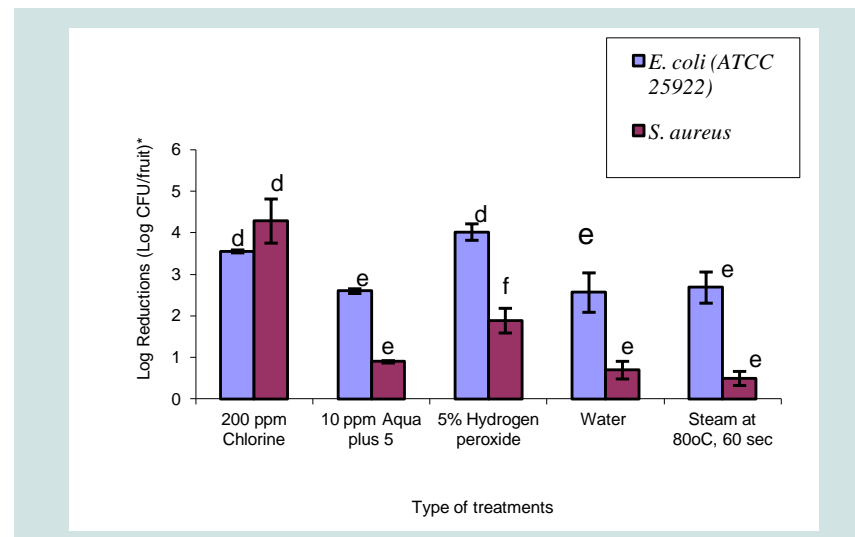

Figure 1: Comparison of various treatments on E.coli and S. aureus inoculated on to surface of star fruit skin.

*Values represented by the same colored bars that have same letters indicated on top of each bars showed no significance difference $(p \leq 0.05)$.

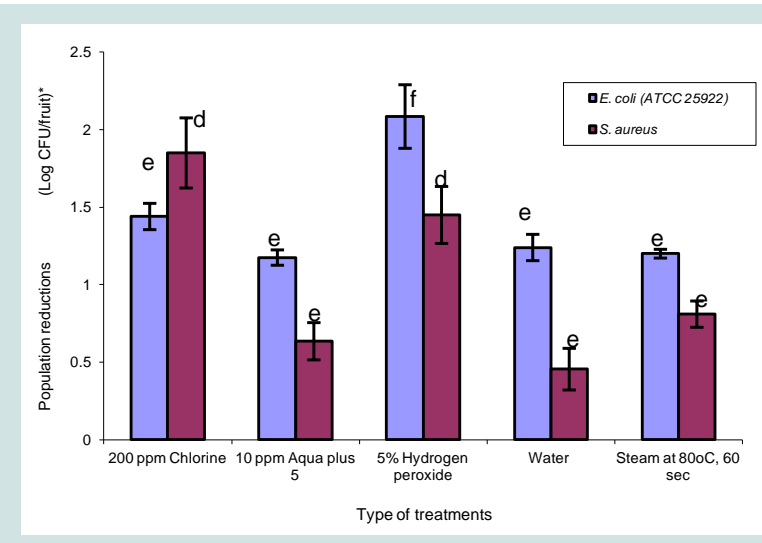

Figure 2: Comparison of various treatments on E.coli and S. aureus inoculated on to surface of guava skin.

*Values represented by the same colored bars that have same letters indicated on top of each bars showed no significance difference $(p \leq 0.05)$.

alone reduced the inoculated levels of $E$. coli by approximately $2 \log$ CFU. However, such effectiveness was not observed in star fruit and guava. In both fruits, treatment with steam at $80^{\circ} \mathrm{C}$ for $60 \mathrm{sec}$ was comparable to that with water. A possible reason may be due to the exposure time. Oranges in Pao and Davis [13] study were dipped in $80^{\circ} \mathrm{C}$ hot water for $2 \mathrm{~min}$ whereas for star fruits and guavas were exposed to $80^{\circ} \mathrm{C}$ steam for only $1 \mathrm{~min}$. The longer time of heat treatment was not recommended because of the death of tissue at these times and temperatures (data not shown). Steam has greater heat capacity than water at same temperature [24]. Thus, theoretically, microbes should be more readily killed by steam as compared to water at the same temperature.

\section{Pineapple}

From Figure 3, it can be seen that 200 ppm chlorine, 10 ppm Aqua plus 5 and water were all ineffective in reducing $S$. aureus and E. coli from surface of pineapple. These treatments were only able to reduce the bacteria cells by $<1 \log$ CFU. The ineffectiveness of these treatments could be explained by the lack of ability of the chemicals to penetrate the fruit surface. Moreover, the roughness of pineapple skin could encourage firm attachment of bacterial cells, which would also shield the bacteria from sanitizing agents.

A solution of $5 \%$ hydrogen peroxide as well as steam seemed to perform better than rest of the treatments. Population reduction of the bacteria was slightly $>1 \log \mathrm{CFU} /$ fruit for hydrogen peroxide and $>2 \log \mathrm{CFU} /$ fruit reduction for steam at $80^{\circ} \mathrm{C}$. Generally one of the limitations in heat sanitization is that heat kills the tissues and cause adverse effects on colour, texture and flavor in fruits [25]. As compared to papaya, mango or tomato, pineapple has a relatively thicker and tougher skin. The skin may help to insulate the flesh. In the present study, steam was more effective than rest of treatments in reducing bacteria population (Figure 3 )

The effectiveness of hydrogen peroxide dip treatment in pineapple as compared to other treatments may possibly depend on two factors. One is the lethality of hydrogen peroxide to bacteria on pineapple surfaces. The other, particularly unique to pineapple is the enhancement of bacterial removal from pineapple surfaces by mechanical action of many small oxygen bubbles. These bubbles are produced at pineapple surfaces by the catalase-hydrogen peroxide 
Citation: Har KK, Perera CO. Efficacy of Sanitizers on Three Types of Tropical Fruits Having Different Skin Characteristics. J Food Processing \& Beverages. 2013;1(1): 4.

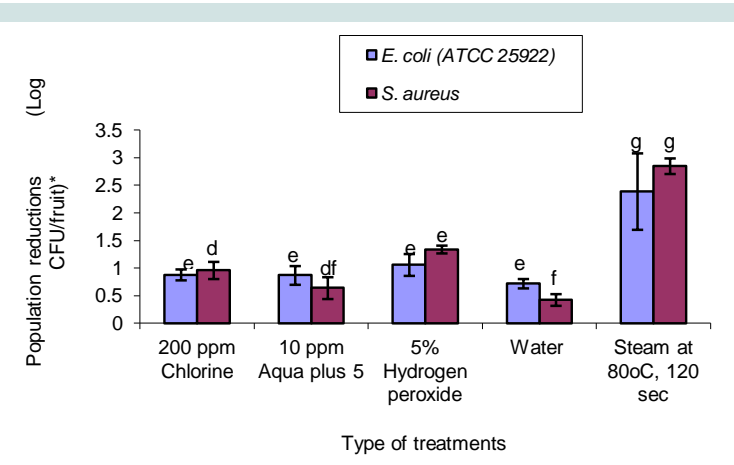

Figure 3: Comparison of various treatments on E.coli and S. aureus inoculated on to surface of pineapple skin.

*Values represented by the same colored bars that have same letters indicated on top of each bars showed no significance difference ( $p \leq 0.05)$.

reaction, which may aid in dislodging the attached microorganisms from the surface. Similar observations were made by Sapers and others [26] when mushrooms were treated with hydrogen peroxide and the treatment was found to be effective in suppressing bacterial blotch development.

\section{Conclusion}

Many of the sanitizer treatments used for temperate fruits was unsuitable for the tropical fruits reported in this study. The differences in the level of removal of bacteria in star fruit, guava and pineapple may be due to the morphology of the surfaces of these fruits. Star fruit is protected by a relatively smooth and waxy cuticle that can possibly discourage bacteria from adhering to its surface. Thus loose bacterial cells are easily removed from star fruit resulting in higher population reductions than from guava or pineapple. Most of the same treatments were only able to reduce the bacteria cells by $<1 \log$ CFU in the case of pineapple. The ineffectiveness of these treatments could be explained by the lack of ability of the chemicals to penetrate fruit surface. Moreover, the roughness of pineapple skin could encourage firm attachment of bacteria cells and also shield them from sanitizing agents. None of the treatments the fruits received was capable of bringing about a 5-log reduction as recommended by the FDA for minimally processed fruits. Therefore the effect of higher concentration of the sanitizers should be further considered.

\section{References}

1. Beckel K (2012) State of the industry 2012

2. Dean L (2013) Growing strong: Meeting consumer demand key to keeping fresh-cut healthy in 2013

3. Berger CN, Sodha SV, Shaw RK, Griffin PM, Pink D, et al. (2010) Fresh fruit and vegetables as vehicles for the transmission of human pathogens. Environ Microbiol 12: 2385-2397.

4. Beuchat LR (2002) Ecological factors influencing survival and growth of human pathogens on raw fruits and vegetables. Microbes Infect 4: 413-423.

5. FDA (2013) Outbreaks Associated with Fresh and Fresh-Cut Produce Incidence, Growth, and Survival of Pathogens in Fresh and Fresh-Cut Produce.

6. Altekruse SF, Swerdlow DL (1996) The changing epidemiology of foodborne diseases. Am J Med Sci 311: 23-29.

7. Sleator RD, Hill C (2007) Food reformulations for improved health: A potential risk for microbial food safety? Med Hypotheses 69: 1323-1324.

8. Skovgaard N (2007) New trends in emerging pathogens. Int J Food Microbiol
120: $217-224$.

9. FDA (2008) Guidance for Industry: Guide to Minimize Microbial Food Safety Hazards of Fresh-cut Fruits and Vegetables.

10. Roberts R, Reymond ST (1994) Chlorine dioxide for reduction of postharvest pathogen inoculum during handling of tree fruits Appl Environ Microbiol 60: 2864-2868.

11. Reina LD, Fleming HP, Humphries EG (1995) Microbiological control of cucumber hydrocooling water with chlorine dioxide. J Food Prot 58: 541-546.

12. Sapers GM, Miller RL, Mattrazzo AM (1999) Effectiveness of sanitizing agents in inactivating Escherichia coli in golden delicious apples $\mathrm{J}$ Food Sci 64: 734-737.

13. Pao S, Davis CL (1999) Enhancing microbiological safety of fresh orange juice by fruit immersion in hot water and chemical sanitizers. J Food Prot 62 756-760.

14. Wu FM, Beuchat LR, Wells JG, Slutsker L, Doyle MP, et al. (2001) Factors influencing the detection and enumeration of Escherichia coli $0157: \mathrm{H} 7$ on alfalfa seeds. Int J Food Microbiol 71: 93-99.

15. Beuchat LR, Ward TE, Pettigrew CA (2001) Comparison of chlorine and a prototype produce wash product for effectiveness in killing Salmonella and Escherichia coli O157:H7 on alfalfa seeds. J Food Prot 64: 152-158.

16. Archer GL, Crossley KB (1997) The Staphylococci in human disease. pp 1-38, Churchill Livingstone Publishers, New York.

17. Rossoni EM, Gaylarde CC (2001) Comparison of sodium hypochlorite and per-acetic acid as sanitizing agents for steel food processing surfaces using epifluorescence microscopy. Int J Food Microbiol 61: 81-85.

18. Behrsing J, Winkler S, Franz P, Premier R (2000) Efficacy of chlorine for inactivation of Escherichia coli on vegetables. Postharvest Biol. Technol 19: 187-192.

19. Han Y, Sherman DM, Linton RH, Nielson SS, Nelson PE (2000) The effects of washing and chlorine dioxide gas on survival and attachment of Escherichia coli 0157:H7 to green pepper surfaces. Food Microbiol 17: 521-533.

20. Park CM, Beuchat LR (1999) Evaluation of sanitizers for killing Escherichia coli 0157:H7, Salmonella and naturally occurring microorganisms on cantaloupes, honeydew melons and asparagus. Dairy Food Environ Sanit 19: $842-847$

21. Yu K, Newman MC, Archibald DD, Hamilton-Kemp TR (2001) Survival of Escherichia coli $\mathrm{O} 157: \mathrm{H} 7$ on strawberry fruit and reduction of the pathogen population by chemical agents. J Food Prot 64: 1334-1340.

22. Juven BJ, Pearson MD (1996) Antibacterial effect of hydrogen peroxide and the methods for its detection and quantitation. J Food Prot 59: 1233-1241.

23. Beuchat LR (1999) Survival of enterohemorrhagic Escherichia coli O157:H7 in bovine feces applied to lettuce and the effectiveness of chlorinated water as a disinfectant. J Food Prot 62: 845-49.

24. Gardner JF, Peel MM (1992) Introduction to sterilization, disinfection and infection control. pp 153-170, Churchill Livingstone Publishers, Melbourne, Australia.

25. Breidt R, Hayes JS, Fleming HP (2000) Reduction of microflora on whole pickling cucumbers by blanching. J Food Sci 65: 1354-1358

26. Sapers GM, Miller RL, Cooke RH, Choi SW (1994) Enzymatic browning control in minimally processed mushrooms. J Food Sci 59: 1042-1047.

\section{Copyright}

(C) 2013 Har KK, et al. This is an open access article distributed under the Creative Commons Attribution License, which permits unrestricted use, distribution, and reproduction in any medium, provided the original work is properly cited. 